\title{
Current Harmonic Reduction on Source Side by using ANN Controller
}

\author{
G. Srinivas ${ }^{1}$ \\ Assistant Professor, \\ Department of Electrical and Electronics Engineering, \\ Vignan Institute of Technology and Science, Telangana.
}

\author{
P. Sai Kumar' ${ }^{2}$, V. Hyndavi ${ }^{3}$, K. Anuhya ${ }^{4}$ \\ U.G. Student, \\ Department of Electrical and Electronics Engineering, \\ Vignan Institute of Technology and Science, \\ Telangana.
}

\begin{abstract}
Power system engineers face a serious problem due to harmonics produced by various nonlinear loads as they negatively affect the quality of the power system. As of late, numerous discoveries have focused on diminishing the harmonics by presenting different filtering strategies at the load side. This paper presents another idea of diminishing current harmonics at the source side of several non-linear loads utilizing SAPF and ANN controller. To examine the presentation of this recognizable proof strategy, the study has been practiced utilizing simulation with MATLAB Simulink power System Toolbox. The simulation study consequences of this novel procedure contrasted with other comparable techniques are found very palatable by guaranteeing great satisfying qualities and high system stability.
\end{abstract}

\section{Keywords-ANN, non-linear loads, SAPF and harmonics}

\section{INTRODUCTION}

The extensive utilization of non-linear loads is prompting a variety of unwanted wonders in the operation of power system. Among these, current and voltage harmonics are most significant. Customarily, active filter has been utilized to mitigate line current harmonics. However, they introduce resonance in the system and tend to be cumbersome. Along these lines, active power filters have gotten more well-known than passive filters as they compensate reactive power as well as harmonics at the same time.

The active power filter topology can be connected in series or shunt or combination of both. Shunt active filter is more well-known than series active filter in light of the fact that the vast majority of industries require harmonic current compensation. Various sorts of active filters have been proposed to build the quality of the power system. The characterization depends upon the following measures.

- System parameters to be compensate (for example harmonic currents, power factor and harmonic voltages)

- Technique utilized for evaluating the fundamental current and voltage.

Voltage source inverters which are current controlled can be used with a proper control system to accomplish the active power filter effectively.
II. HARMONICS AND IT'S EFFECTS

Power systems are designed to function at frequencies of 50 or $60 \mathrm{~Hz}$. However, some loads can produce voltages and currents with frequencies greater than the fundamental frequency of 50 or $60 \mathrm{~Hz}$. Electric pollution namely, Harmonic distortion can be caused due to this higher frequency components There are two types of harmonics present in a power system:

- Synchronous harmonics

- Asynchronous harmonics

Harmonics are aware to musicians like the nuances of an instrument. These are the integer multiples of the fundamental frequency of the instrument which are formed by a series of standing waves of increasing order. Exactly the same operation occurs in power circuits where non-linear loads create harmonic currents which are integer multiples of the fundamental supply frequency.

Joseph Fourier has introduced the concept of harmonics in the early $19^{\text {th }}$ century. Fourier has shown that all nonsinusoidal periodic signals can be represented by an infinite series of sinusoids with discontinuous frequencies as indicated by Equation (2.1).

$$
i(t)=I_{0}+\sum_{h=1}^{\alpha} I_{h} \cos \left(h \omega t+\varphi_{h}\right)
$$

The component $I_{0}$ in the Fourier series is the direct component. The first term of the sum with the index $h=1$ is the fundamental of the signal. The rest of the series components are called the harmonics of the range $h$.

Fig. 1 Shows the form of a wave containing the third harmonic $(h=3)$. In the three-phase electric grid, the principle harmonic components are the harmonics of ranges $(6 * h \pm 1)$.

Transformer energizing current, arc furnaces, rectifiers and numerous different loads will produce harmonics in the utility lines. Most utilities limit the reasonable harmonic current levels to the values shown in IEEE 519. 


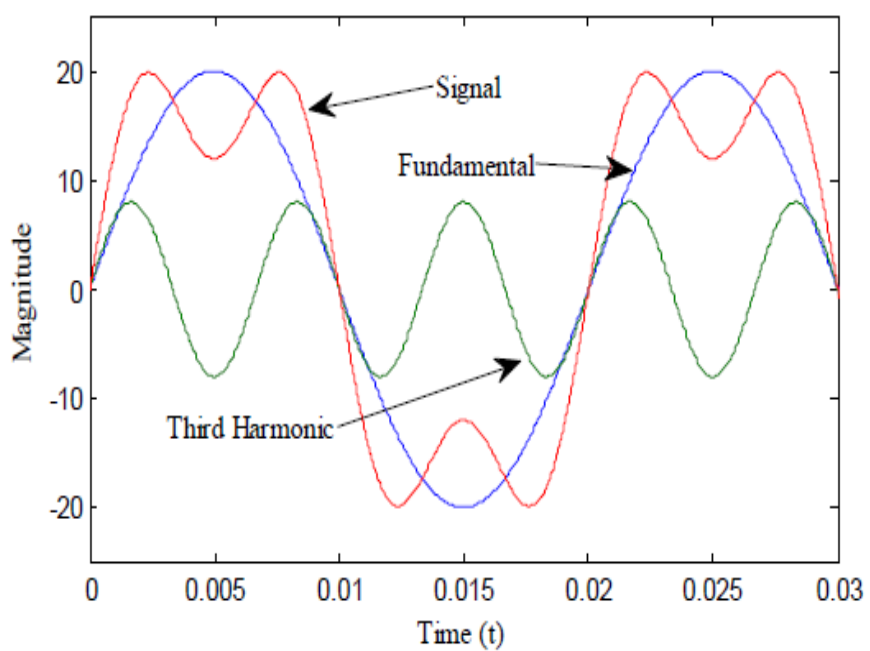

Fig. 1: Harmonic Signal and its Fundamental frequency

The total harmonic distortion of a signal is an estimate of the harmonic distortion present in current or voltage. It is calculated as the square root of the total powers of all harmonic components to the power of the fundamental frequency. Harmonic distortion is caused when there is an introduction of waveforms at frequencies in duplicates of the fundamental.

$$
T H D(\%)=\frac{\sqrt{\sum_{i=2}^{Q} x_{i}^{2}}}{\left|x_{1}\right|}
$$

Harmonics affect different equipment's differently. Some of the detrimental effects caused by harmonics are:

- Premature aging of materials which forces its replacement, in addition to an initial over sizing of these materials.

- The overloading of the grid which implies to increase the nominal power and to oversize the installations, causing more and more losses.

- The current distortions cause sudden triggers and the stop of production equipment's.

These material costs, energetic and production losses affect the competitiveness and the productivity of factories and companies.

> Capacitors: The inductance of the power system can resonate with capacitors at certain harmonic frequencies, causing the development of huge currents and voltages. Increased currents and voltages cause breakdown of dielectric material inside capacitors, which, thus, makes the capacitors to heat. As capacitor dielectrics dry out, they are less fit for disseminating heat, and become significantly increasingly vulnerable to harm from harmonics. As this deterioration continues, short circuits or capacitor blast can happen.

$>$ Transformers: The harmonic voltages can cause a higher transformer voltage and insulation constraints, with a consequent heating of the transformer, a reduced duration, an increase in the copper and iron losses due to hysteretic and eddy currents, and insulation stress.
> Motors: Harmonic voltages can cause motor heating, produce mechanical vibrations and noise, pulsating torques, increase in eddy currents and hysteresis losses in the stator and rotor windings, diminished proficiency, reduction of life of motor.

$>$ CBs and Fuses: If the distortion results in a higher level of di/dt at zero crossing, load interruption can be made difficult than for a sinusoidal waveform. Fuses malfunction under the influence of harmonics.

$>$ Watt-hour meters: Induction disks are calibrated for accurate operation on the fundamental frequency only. Harmonics generate additional torque on these discs, triggering incorrect operation and improper readings.

$>$ Rotating Machines: Harmonics increase dielectric losses in insulation, raise its hot spot temperature, cause premature failure, increase iron and copper losses and reduce the overall operational efficiencies. Fields produced by some harmonics, in the air gap, rotate in a reverse direction. This can cause cogging, crawling or even shaft vibrations

$>$ Telephones: The most common interference mechanism between power system harmonics and the telephone circuit is induction coupling by the power line magnetic field and the loop formed by the telephone conductor and ground.

> Conductor's: Skin effect and proximity effect both proportional to the square of frequency and hence increase with increasing harmonics.

The IEEE detail necessitates that harmonic distortion of the current waveform be restricted to $5 \%$. However, some engineers believe that running a plant with such high harmonic distortion can lead to significant energy losses and shorten the life of equipment and suggest that the total harmonic distortion should not reach $1.5 \%$ under operating conditions.

Modern solutions have been proposed as effective solutions for eliminating harmonics from the electrical network in order to overcome the drawbacks of old-style methods such as passive filters. Among these solutions, we find two categories that are most used:

- Active filters (series, shunt, or a combination of both same as Unified Power Quality Conditioner (UPQC)).

- Hybrid filters composed simultaneously of active and passive filters.

\section{ACTIVE POWER FILTER}

Active power filters (APF) have the function of generating harmonic currents or voltages so that the network current or the voltage waves retain the original sinusoidal form. The APF can be connected in series (Series APF), shunt (SAPF) to compensate for voltage or current harmonics respectively. Or it can be combined with passive filters to build the hybrid filters (HAPF) which can mitigate both current and voltage harmonics. 
Active filters are quite new to the world of harmonic removal devices. This type of filters is based on power electronic devices and are much costlier than passive filters. They are used in difficult times where the passive filters do not work properly due to resonance problems and they do not have interference with other elements installed anywhere in the power system.

Active filters have many other advantages over the oldstyle methods of harmonic compensation such as:

- Adapting with the change of the loads.

- Selective compensation of harmonics is possible.

- Limitations of the power compensation.

- Compensation of reactive power is possible.

The idea of utilizing active power filters to alleviate harmonic problems and to remunerate reactive power was introduced over two eras back. It has demonstrated its capability to regulate the network current and to improve the quality of the power. The hypotheses and utilizations of active power filters have gotten progressively famous and have pulled in incredible consideration. Without the downsides of passive harmonic filters, such as component maturing and resonance problems, the APF has all the earmarks of being a feasible answer to compensate for reactive power and eliminate harmonic currents. As we stated earlier, SAPF is connected in shunt with the non-linear load to act like another controlled non-linear load. In the event of reactive power compensation, this load will be resistive. Otherwise. it acts as inductive or capacitive linear load.

The shunt active power filter compensates for harmonic currents by injecting equivalent but inverse harmonic compensation currents into the network. In this situation, the shunt active power filter functions as a current source which injects the harmonic components produced by the load but $180^{\circ}$ out of phase. This principle is applicable to any type of load considered as a harmonic source. In this way, the energy distribution system considers the non-linear load and the APF as an ideal resistance.

The control circuit is operated with phase lock loop, proportional integral controller and hysteresis controller which is used to generate the gating pulses for the 4-leg inverter and is carried out at load side with non-linear unbalanced load.

The purpose of active power filtering is to mitigate for the harmonic currents generated by non-linear loads and to guarantee the retain of sinusoidal form of currents and voltages. The primary step in active filtering is the extraction of the harmonic currents that are to be injected into the network. Good harmonic extraction is a important for a good active power filter.

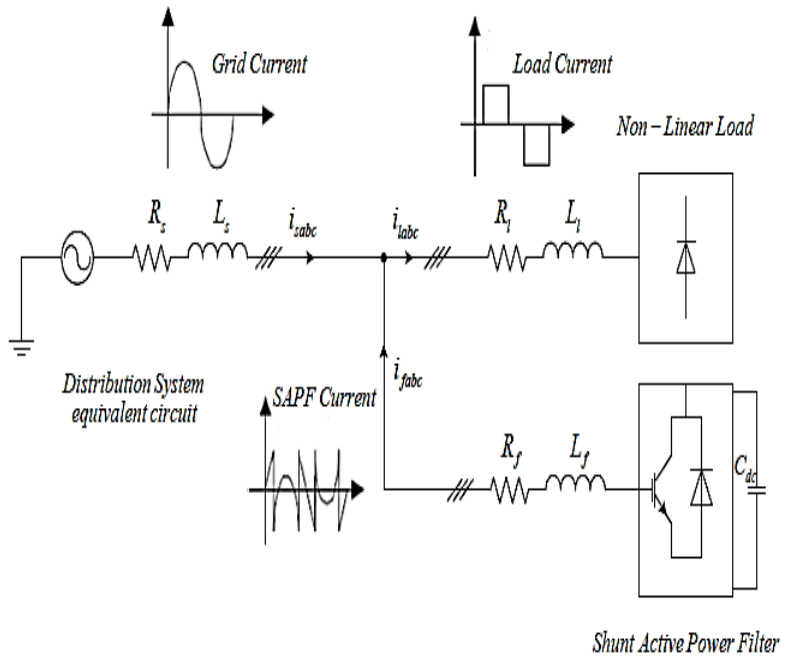

Fig. 2: Representation of Shunt Active Power Filter

Most APFs were planned on the basis of the instantaneous theory of active and reactive power (p-q), first proposed by Akagi et al in 1983. Initially, it was developed only for threephase systems with neutral wireless system, then worked by Watanabe and Aredes for three-phase four wire electrical networks. The method utilizes the change of deformed currents from a three phase abc frame to a two-phase $\alpha \beta$ stationary frame. The essential thought is that the harmonic currents caused by non-linear loads in the supply system can be compensated by other non-linear controlled loads. The three-phase supply voltages (ua, ub, uc) and currents (ia, ib, ic) are transformed using the Clarke transformation (or $\alpha-\beta)$ in a different coordinate system which produces prompt active and reactive power components. This transformation can be seen as a estimate of the three-phase quantities on a stationary two-axis reference system. The Clarke transformation for the voltage variables is given by

$$
\left[\begin{array}{l}
u_{\infty} \\
u_{\beta} \\
u_{0}
\end{array}\right]=\sqrt{\frac{2}{3}}\left[\begin{array}{ccc}
1 & -\frac{1}{2} & -\frac{1}{2} \\
0 & \frac{\sqrt{3}}{2} & -\frac{\sqrt{3}}{2} \\
\frac{1}{\sqrt{2}} & \frac{1}{\sqrt{2}} & \frac{1}{\sqrt{2}}
\end{array}\right]\left[\begin{array}{l}
u_{a} \\
u_{b} \\
u_{c}
\end{array}\right]
$$

Similarly, this transform can be applied on the distorted load currents to give:

$$
\left[\begin{array}{l}
i_{l \propto} \\
i_{l \beta} \\
i_{l 0}
\end{array}\right]=\sqrt{\frac{2}{3}}\left[\begin{array}{ccc}
1 & -\frac{1}{2} & -\frac{1}{2} \\
0 & \frac{\sqrt{3}}{2} & -\frac{\sqrt{3}}{2} \\
\frac{1}{\sqrt{2}} & \frac{1}{\sqrt{2}} & \frac{1}{\sqrt{2}}
\end{array}\right]\left[\begin{array}{l}
i_{l a} \\
i_{l b} \\
i_{l b}
\end{array}\right]
$$

The instantaneous active power $\mathrm{p}(\mathrm{t})$ is defined by:

$$
\mathrm{p}(\mathrm{t})=u_{\sigma_{i}} i_{l a}+u_{b} i_{i b}+u_{c} i_{i e}
$$

This expression can be given in the stationary frame by:

$$
\left\{\begin{array}{c}
p(t)=u_{x} i_{i x}+u_{\beta} i_{i \beta} \\
p_{n}(t)=u_{n} i_{i n}
\end{array}\right.
$$


Where, $\mathrm{p}(\mathrm{t})$ is the instantaneous active power, $\mathrm{p} 0(\mathrm{t})$ is the immediate homo-polar sequence power. Also, the instantaneous reactive power can be given by:

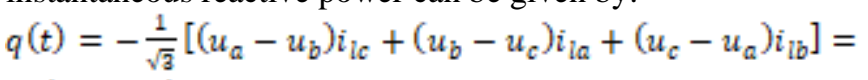
$u_{\alpha} i_{1 \beta}-u_{\beta} i_{\eta \alpha}$

It is important to note that the instantaneous reactive power $\mathrm{q}(\mathrm{t})$ means more than the just reactive power. The instantaneous reactive power takes into account all the harmonics of current and voltage, whereas the usual reactive power considers only the fundamentals of current and voltage.

From equations (3.4) and (3.5) the active and reactive instantaneous power can be given in the form of a matrix:

$$
\left[\begin{array}{l}
p \\
q
\end{array}\right]=\left[\begin{array}{cc}
u_{\infty} & u_{\beta} \\
-u_{\beta} & u_{\alpha}
\end{array}\right]\left[\begin{array}{l}
i_{i \alpha} \\
i_{\Pi \beta}
\end{array}\right]
$$

Each individual of the active and reactive instantaneous power possesses a direct component and an alternative component- "The direct component represents the power of the fundamentals of currents and voltages. The alternative term represents the power of the harmonics of currents and voltages".

To separate the harmonics from the fundamental load currents, it suffices to separate the direct term of the instantaneous power from the alternating one. A Low Pass Filter (LPF) with a feed-forward effect can be used to accomplish this task. Fig. 3 shows the principle of this extraction filter.

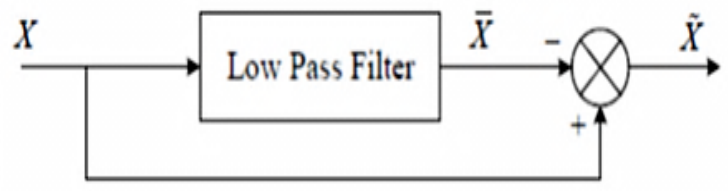

Fig. 3: Low Pass Filter with Feed-Forward.

After the separation, the harmonic components of the load currents are obtained using the inverse of equation (3.6) which provides:

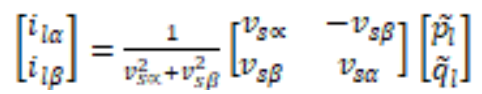

Where, the ${ }^{\mathrm{m}}{ }^{\mathrm{m}}$ sign points to the alternating.

The APF reference current can be then given by:

$$
\left[\begin{array}{l}
i_{f a}^{*} \\
i_{f b}^{*} \\
i_{f c}^{*}
\end{array}\right]=\sqrt{\frac{2}{a}}\left[\begin{array}{cc}
1 & 0 \\
-\frac{1}{2} & \frac{\sqrt{a}}{2} \\
-\frac{1}{2} & -\frac{\sqrt{3}}{2}
\end{array}\right]\left[\begin{array}{l}
\tilde{i}_{l \alpha} \\
\tilde{i}_{1 \beta}
\end{array}\right]
$$

In the case of reactive power compensation, it is sufficient to send the reactive power $\mathrm{q}(\mathrm{t})$ directly to the reference current calculation block without using an extraction filter.

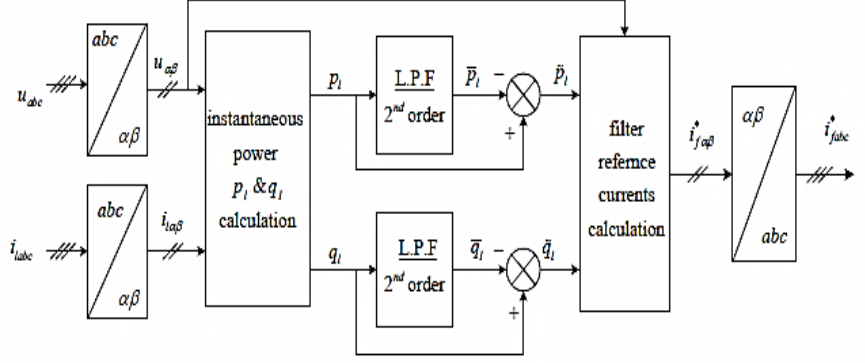

Fig. 4: Principle of Instantaneous Active and Reactive Power Theory

\section{IV.ARTIFICIAL NEURAL NETWORK (ANN) CONTROLLER}

The Artificial Neural Network (ANN) controller is broadly used in various fields of technical and non-technical applications. ANN has generated great interest in power system applications due to its simple in structure, ease of its training process, quick response, high performance and flexibility. ANN has inherent intelligent speculation or thought to take the decision based on the all-around prepared information, inclination and adjustment procedure. The ANN controller was divided and categorized into "ADALINE

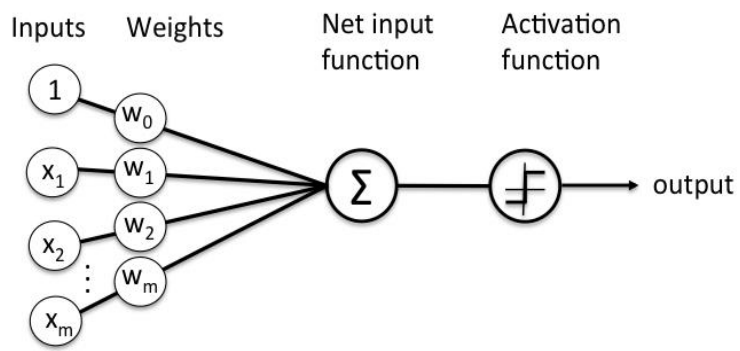

(Adaptive linear element), MADALINE (Many ADALINE), Widrow-Hoff, Perceptron, Radial base function (RBF), Hebbian, Backpropagation (BP), Competitive Grossberg and Hopfield".

In power system, ANN controllers are very well known for their ability to diminish harmonics. In the proposed model system ADALINE (Adaptive linear element), the structure of the ANN controller is utilized in shunt active filter which compensates for current control as a result of its simple and straightforward structure and quick response. Using the ANN controller provides a quick response by reducing the rise time by approximately $33 \%$ as compared with PI controller.

Fig. 5: Schematic diagram of ADALINE network

This schematic diagram consists of two levels, named as input level with a number with $\mathrm{n}$ inputs and one output level with two outputs and a multi-layer feed forward ADALINE Neural Network is used. The ANN learning process is very different it goes through supervised learning and unsupervised learning or self-learning. The ADALINE Neural Network accomplishes a weight correction depending upon output error value. 


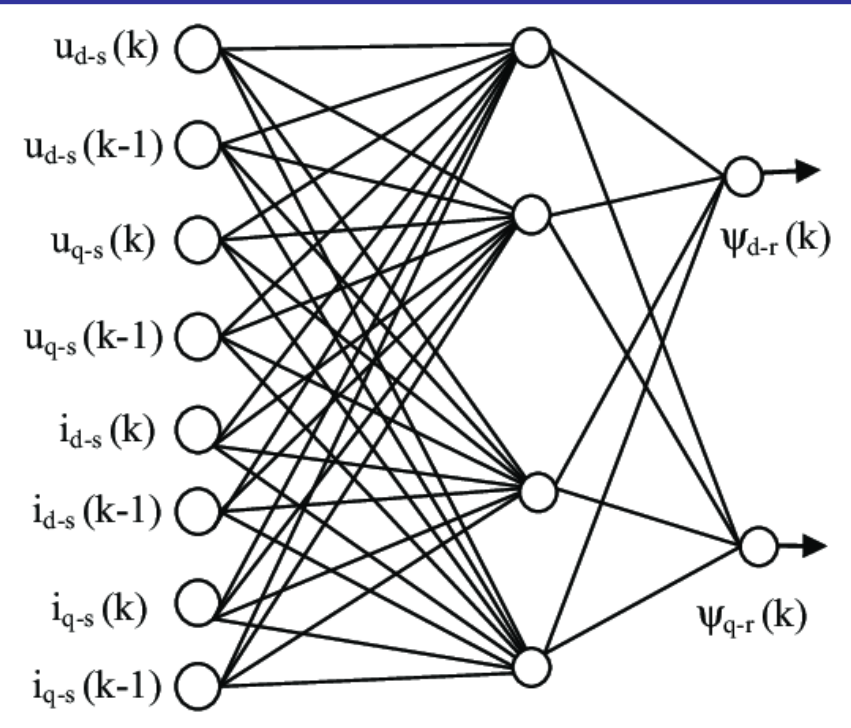

Fig. 6: Schematic representation of multilayer ADALINE network.

\section{MATLAB SIMULATION AND RESULTS}

The renewable energy source (RES) integrated at the distribution level is called Distributed Generation (DG). The public service is concerned about the high level of penetration of intermittent RES into distribution networks, as it can pose a threat to the network in terms of stability, Power Quality (PQ)and voltage regulation. Therefore, DG systems must comply with rigorous technical and controlling frameworks to ensure safe, reliable and efficient operation of the entire network. With advances in power electronics and digital control technology, DG systems can now be actively controlled to improve system operation with an improved PQ for the PCC. However, the extensive use of equipment based on power electronics and non-linear PCC loads generates harmonic currents that can deteriorate the quality of power.
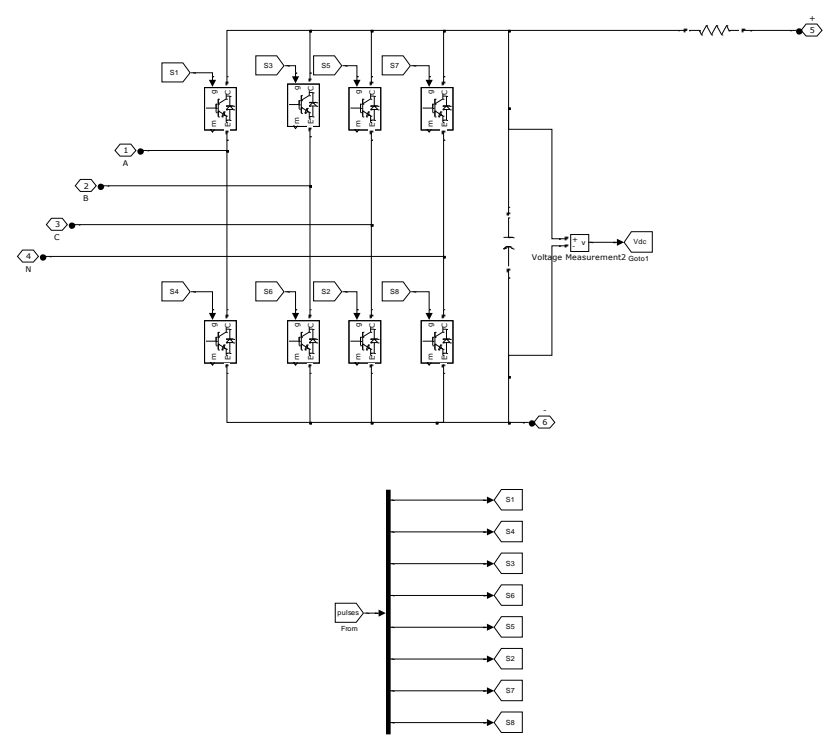

Fig. 8: Four Leg Inverter

To obtain the current reference signals from the active power filter a current reference generator diagram based on $d q$ is used. The synchronized reference signals $\sin (w t)$ and $\cos (w t)$ are gained from a Synchronous Reference Frame (SRF) PLL. These SRF-PLL produces a pure sine waveform even though the system voltage is severely distorted.

The amplitude of the converter reference current must be changed by addition of an active power reference signal $\left(i_{e}\right)$ with the d component to keep the dc voltage constant. By applying inverse Park and Clark transformation the resulting signals $i_{d}$ and $i_{Q}$ are transformed back to a three-phase system. Below Fig 7: Main SIMULINK circuit for the NONLINEAR LOADS with shunt connected APF $\begin{aligned} & \text { Discrete, } \\ & =5 \mathrm{e}-005 \\ & \text { powergui }\end{aligned}$
powat

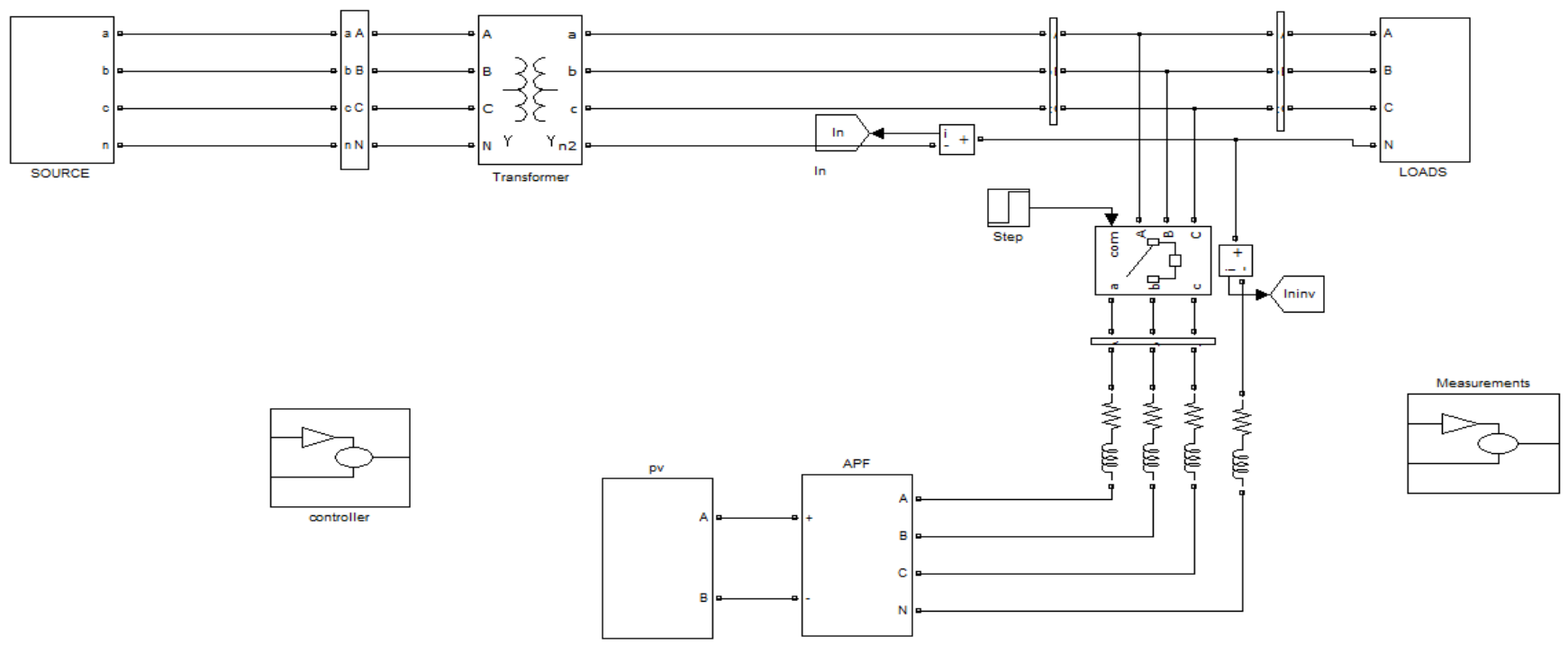


The dc-voltage converter is controlled by a traditional Neural network controller. This is a considerable problem in estimation, since the cost is based only the current references, in order to avoid the use of weighting factors. Generally, these weighting factors are obtained experimentally and are not well defined when different operating conditions are required.

Using MATLAB-SIMULINK the following characteristics are drawn:

\begin{tabular}{|l|l|l|}
\hline Variable & Description & Value \\
\hline $\mathrm{V}_{\mathrm{S}}$ & Source voltage & $55[\mathrm{~V}]$ \\
\hline$F$ & System frequency & $50[\mathrm{~Hz}]$ \\
\hline$V_{d c}$ & dc-Voltage & $162[\mathrm{~V}]$ \\
\hline$C_{\text {de }}$ & dc capacitor & $2200[\mu F]$ \\
\hline$L_{f}$ & Filter inductor & $5.0[\mathrm{mH}]$ \\
\hline $\mathrm{R}_{f}$ & Internal resistance & $0.6[\Omega]$ \\
\hline $\mathrm{T}_{\mathrm{s}}$ & Sampling time & $20[\mu \mathrm{s}]$ \\
\hline $\mathrm{T}_{\mathrm{e}}$ & Execution time & $16[\mu \mathrm{s}]$ \\
\hline
\end{tabular}

Table 1: Specification parameters

The objective of this paper is to verify the current efficiency of the harmonic compensation of the proposed control scheme under different operating conditions. In the simulated results the voltage from phase to neutral source from $\mathrm{t}=0$ to $\mathrm{t}=0.8$.

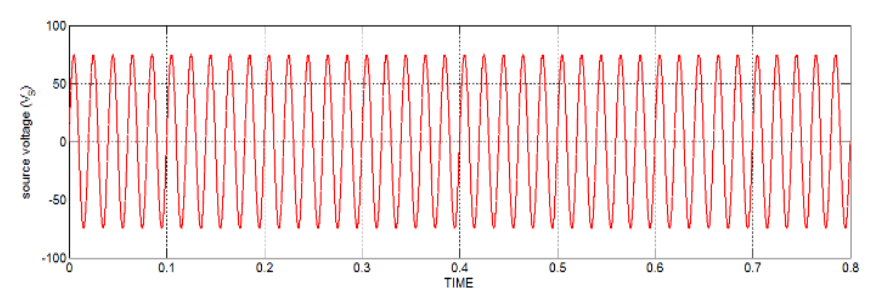

Fig. 9: Phase to Neutral Source Voltage

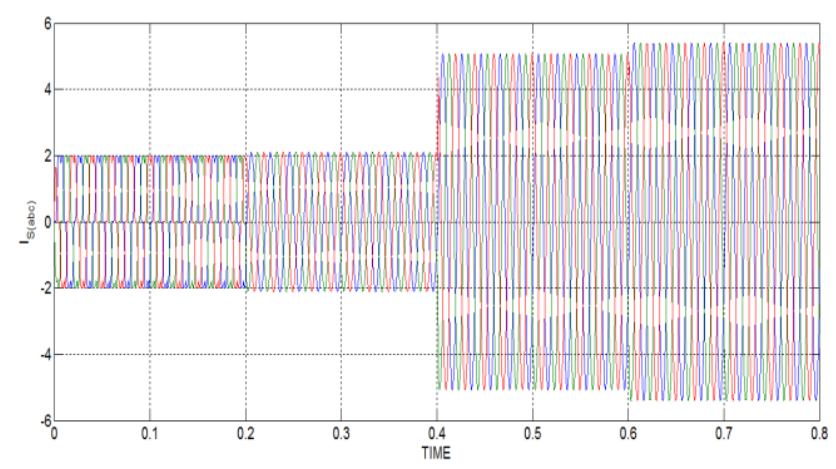

Fig. 10: Source Currents waveform

At $t=0.4$, a phase change of the balanced three-phase load is displayed. The compensated currents of the system, shown remain sinusoidal despite the variation in the amplitude of the load current.

Finally, at $\mathrm{t}=0.6$, a phase change of the single-phase load is introduced into phase $\mathrm{u}$, which is equivalent to a current imbalance of $11 \%$, illustrated. As expected on the load side, a neutral current flow is shown through the neutral conductor $\left(i_{\text {Ln }}\right)$, but no neutral current $\left(i_{\text {sn }}\right)$ is observed on the source side.

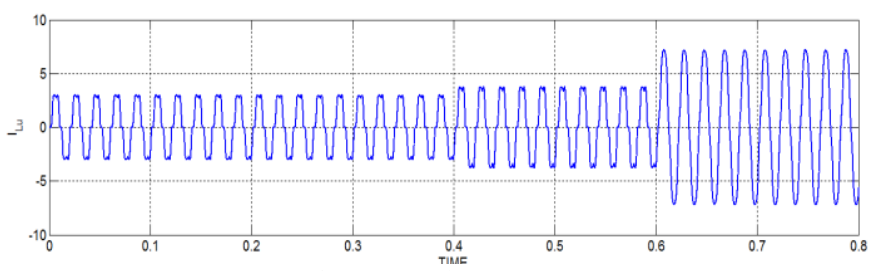

Fig. 11: Load Current

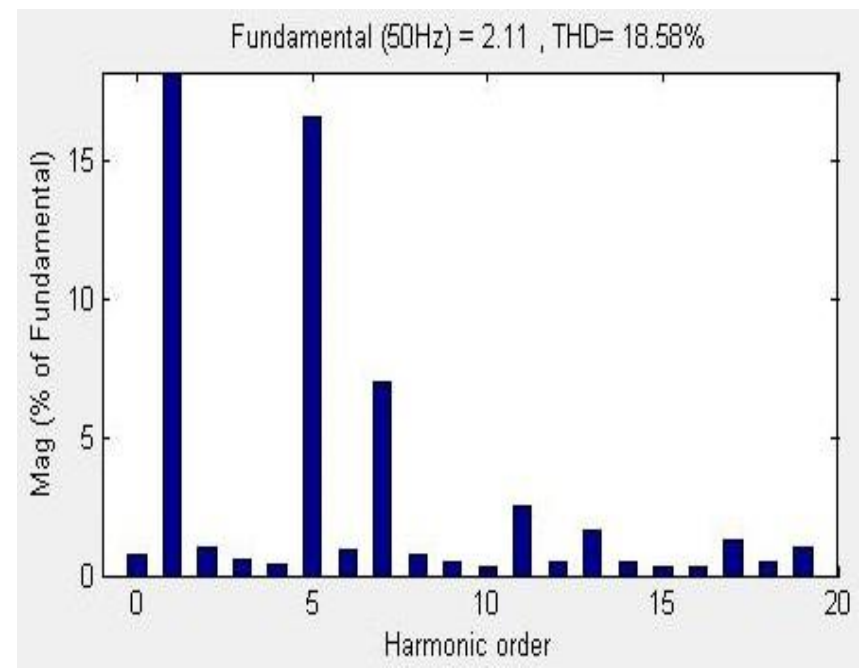

Fig. 12: FFT analysis without ANN

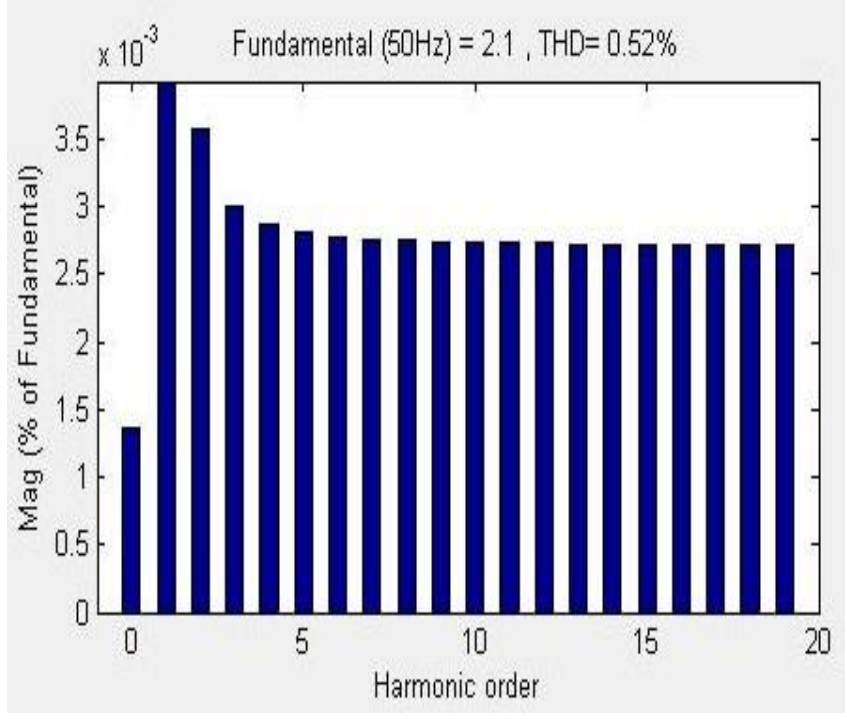

Fig. 13: FFT analysis with ANN

\section{CONCLUSION AND FUTURE SCOPE}

This paper proposes the ANN as an implementation and the THD measurement of three phase voltage and current at grid side is measured. Comparison between the LCL filter associated to the grid using with and without controller simulation is done.

In this thesis, a DC-coupled System has been studied, to improve the power quality at point of common coupling with 3-phase 4-wire distributed generation. The grid interface inverter has been shown to be able to be used effectively for power conditioning without affecting the normal operation of actual power transfer. 
The MATLAB/SIMULINK 2009a simulation model of the proposed system with the connection of renewable energy sources is shown and validated.

Thus, the current imbalance, the current harmonics and the reactive power of the load, due to an asymmetric and nonlinear load connected to the PCC, are effectively compensated so that the network currents are always kept balanced and sinusoidal at unity power factor.

Integrating neural network logic with neural networks and genetic algorithms is now transforming automated intellectual systems in many disciplines.

The performance of the above-mentioned Hysteresis controller based APF can be improved by neural network logic controller \& also neural network techniques.

\section{REFERENCES}

[1] J. H. R. Enslin and P. J. M. Heskes, "Harmonic interaction between large number of distributed power inverters and the distribution network," IEEE Trans. Power Electron., vol. 19, no. 6, pp. 15861593, Nov. 2004.

[2] U. Borup, F. Blaabjerg, and P. N. Enjeti, "Sharing of nonlinear load in parallel-connected three-phase converters," IEEE Trans. Ind. Appl., vol. 37, no. 6, pp. 1817-1823, Nov./Dec. 2001.

[3] P. Jintakosonwit, H. Fujita, H. Akagi, and S. Ogasawara, "Implementation and performance of cooperative control of shunt active filters for harmonic damping throughout a power distribution system," IEEETrans. Ind. Appl., vol. 39, no. 2, pp. 556-564, Mar./Apr. 2003.

[4] S. B. Kjaer, J. K. Pedersen, and F. Blaabjerg, "A review of singlephase grid-connected inverters for [6] F. Blaabjerg, R. Teodorescu, M. Liserre, and A. V. Timbus, "Overview of control and grid synchronization for distributed power generation systems," IEEE Trans.

[5] J. M. Carrasco, L. G. Franquelo, J. T. Bailiwick, E. Galvan, R. C. P. Guisado, M. Á. M. Prats, J. I. León, and N. M. Alfonso, "Power electronic systems for the grid integration of renewable energy sources: A survey," IEEE Trans. Ind. Electron., vol. 53, no. 4, pp. 1002-1016, Aug. 2006.

[6] B. Renders, K. De Gusseme, W. R. Ryckaert, K. Stockman, L. Vandevelde, and M. H. J. Bollen, "Distributed generation for mitigating voltage dips in low-voltage distribution grids," IEEE Trans. Power.Del., vol. 23, no. 3, pp. 1581-1588, Jul. 2008.

[7] V. Khadkikar, A. Chandra, A. O. Barry, and T. D. Nguyen, "Application of UPQC to protect a sensitive load on a polluted distribution network," in Proc. Annu. Conf. IEEE Power Eng. Soc. Gen. Meeting, 2006, pp. 867-872.

[8] M. Singh and A. Chandra, "Power maximization and voltage sag/swellride-through capability of PMSG based variable speed wind energy conversion system," in Proc. IEEE 34th Annu. Conf. Indus. Electron.Soc., 2008, pp. 2206-2211.

[9] J. P. Pinto, R. Pregitzer, L. F. C. Monteiro, and J. L. Afonso, "3phase4-wire shunt active power filter with renewable energy interface," presented at the Conf. IEEE Renewable Energy \& Power Quality, Seville, Spain, 2007.

[10] P. Rodríguez, J. Pou, J. Bergas, J. I. Candela, R. P. Burgos, and D. Boroyevich, "Decoupled double synchronous reference frame PLL for power converters control," IEEE Trans. Power Electron, vol. 22 no. 2, pp. 584-592, Mar. 2007

[11] F. Blaabjerg, R. Teodorescu, M. Liserre, and A. V. Timbus, "Overview of control and grid synchronization for distributed power generation systems," IEEE Trans. Ind. Electron., vol. 53, no. 5, pp. 1398-1409, Oct. 2006.

[12] M. Calais, J. Myrzik, T. Spooner, and V. G. Agelidis, "inverters for single-phase grid connected photovoltaic systems - an overview", in Proc. 33th IEEE Power Electronics Specialists Conf. (PESC'02), Cairns, Australia, June 23-27, 2002.

[13] F. Mekria, Mach, Nadia, "Comparative study of voltage controllers for series active power filter, Electric Power Syst.” Res. 80 (6) (2010) $615-626$.
[14] B. Singh, A. Chand, "A review of active filters for power quality improvement”, IEEE Trans. Industrial. Electron. 46 (5) (1999) 960971.

[15] S. Herrera, P. Salmeron, "Instantaneous reactive power theory: a comparative evaluation of different formulations", IEEE Trans. Power Delivery 22 (1) (2007) 595-604,

[16] Joshi, Sathish Goud, "Artificial neural network-controlled shunt active power filter for power quality improvement”, Int. Res. J. Eng. Technol. 2 (4) (2015) 377-383.

[17] P. Salmeron, R. Herrera, R. Vazquez, "A new approach for threephase loads compensation based on the instantaneous reactive power theory, Electric Power Syst.” Res. 78 (2008) 605-61. 